\title{
Evaluating Montessori Education
}

\author{
Angeline Lillard ${ }^{1 *}$ and Nicole Else-Quest ${ }^{2}$ \\ An analysis of students' academic and social scores compares a Montessori school with \\ other elementary school education programs.
}
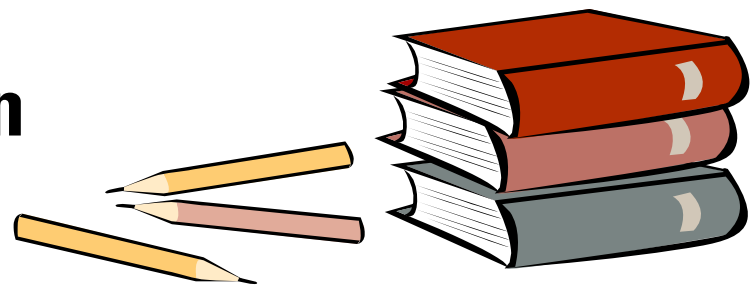

$\mathrm{M}$ ontessori education is a 100 -yearold method of schooling that was first used with impoverished preschool children in Rome. The program continues to grow in popularity. Estimates indicate that more than 5000 schools in the United States - including 300 public schools and some high schools - use the Montessori program. Montessori education is characterized by multi-age classrooms, a special set of educational materials, student-chosen work in long time blocks, collaboration, the absence of grades and tests, and individual and small group instruction in both academic and social skills (1). The effectiveness of some of these elements is supported by research on human learning (2).

We evaluated the social and academic impact of Montessori education. Children were studied near the end of the two most widely implemented levels of Montessori education: primary (3- to 6-year-olds) and elementary (6- to 12-year-olds). The Montessori school we studied [located in Milwaukee, Wisconsin (3)], which served mainly urban minority children, was in its ninth year of operation and was recognized by the U.S. branch of the Association Montessori Internationale (AMI/USA) for its good implementation of Montessori principles (4).

Because it was not feasible to randomly assign children to experimental and control educational groups, we designed our study around the school lottery already in place. Both the experimental and the control group had entered the Montessori school lottery; those who were accepted were assigned to the experimental (Montessori) group, and those who were not accepted were assigned to the control (other education systems) group. This strategy addressed the concern that parents who seek to enroll their child in a Montessori school are different from parents who do not. It is crucial to control for

${ }^{1}$ Department of Psychology, University of Virginia P.O. Box 400400, Charlottesville, VA 22904, USA. ²Department of Psychology, University of Wisconsin, Madison, WI 53202, USA.

*Author for correspondence. E-mail: lillard@virginia.edu this potential source of bias, because parents are the dominant influence on child outcomes (5).

\section{Recruitment}

We contacted parents of children who had entered the Montessori school lottery in 1997 and 2003 and invited them to be in the study. All families were offered $\$ 100$ for participation.

Because the lottery, which was conducted by the school district, was random, the Montessori and control groups should contain similar children. Ninety percent of consenting parents filled out a demographic survey. Parents from the Montessori and control groups had similar average incomes ( $\$ 20,000$ to $\$ 50,000$ per year) at each student age level. This addressed a concern with a retrospective lottery loser design that the final samples might be different for reasons other than the treatment. Another variable, ethnicity, was not surveyed because parent income contributes more to child outcomes than does ethnicity (6). We were also concerned that requesting ethnicity data would reduce participation in this racially divided city.

Overall, 53 control and 59 Montessori students were studied (table S1). The 5-year-old group included 25 control and 30 Montessori children, and the 12-year-old group included 28 control and 29 Montessori children. Gender balance was imperfect, but gender

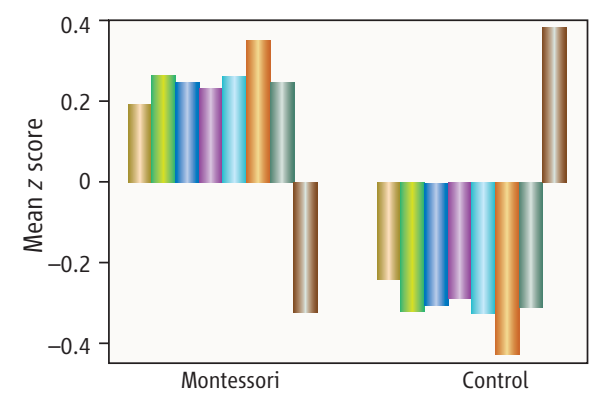

nu letter-word

W] word attack

E. W] applied math

10. False belief (social cognition)

$\begin{array}{ll}\text { III } & \text { Refers to justice } \\ \text { Positive shared play }\end{array}$

Card sort (executive function) Ambiguous rough play

Results for 5-year-olds. Montessori students achieved higher scores (converted to average $z$ scores) for both academic and behavioral tests (18). did not contribute significantly to any of the differences reported here. Children at the Montessori school were drawn from all six classrooms at the primary level and all four at the upper elementary level. The control children were at non-Montessori schools: 27 public inner city schools (40 children) and 12 suburban public, private/voucher, or charter schools (13 children). Many of the public schools had enacted special programs, such as gifted and talented curricula, language immersion, arts, and discovery learning.

Children in both groups were tested for cognitive/academic and social/behavioral skills that were selected for importance in life, not to examine specific expected effects of Montessori education. Our results revealed significant advantages for the Montessori group over the control group for both age groups.

\section{Results: 5-Year-Olds}

Cognitive/Academic Measures. Seven scales were administered from the Woodcock-Johnson (WJ III) Test Battery (7). Significant differences favoring Montessori 5-year-olds were found on three WJ tests measuring academic skills related to school readiness: Letter-Word Identification, Word Attack (phonological decoding ability), and Applied Problems (math skills) (Figure 1). No difference was expected or found on the Picture Vocabulary test (basic vocabulary) because vocabulary is highly related to family background variables (8). Two WJ tests of basic thinking skills - Spatial Reasoning and Concept Formation-also showed no difference.

Five-year-olds were also tested on executive function, thought to be important to success in school. On one such test, children were asked to sort cards by one rule, switch to a new rule, and (if they did well) then switch to a compound rule. Montessori children performed significantly better on this test. A test of children's ability to delay gratification (a treat) did not indicate statistically significant differences.

Social/Behavioral Measures. Children were given five stories about social problems, such as another child hoarding a swing, and were asked how they would solve each problem (9). 
Montessori children were significantly more likely ( $43 \%$ versus $18 \%$ of responses) to use a higher level of reasoning by referring to justice or fairness to convince the other child to relinquish the object. Observations at the playground during recess indicated Montessori children were significantly more likely to be involved in positive shared peer play and significantly less likely to be involved in rough play that was ambiguous in intent (such as wrestling without smiling).

The False Belief task was administered to examine children's understanding of the mind (10). Recognition that people represent the world in subjective as well as objective ways is a landmark achievement in social cognition (11). Social negotiation and discussion about mental states leads to this advance in children (12). Whereas $80 \%$ (significantly more than chance) of the Montessori 5-year-olds passed, the control children were at chance, with $50 \%$ passing.

\section{Results: 12-Year-Olds}

Cognitive/Academic Measures. Twelve-yearolds were given 5 minutes to complete a story beginning "__ had the best/worst day at school." The Montessori students' essays were rated as significantly more creative and as using significantly more sophisticated sentence structures (Figure 2). Control and Montessori essays were similar in spelling, punctuation, and grammar. Unlike the 5-year-olds, the 12year-olds did not perform differently on the WJ tests. This is surprising, because early reading skills normally predict later reading (13). Either the control group had "caught up" by age 12 to the Montessori children, or the 12-year-old Montessori children were not more advanced in these early reading skills when they were 5 . If the latter, one possible explanation is that the 12-year-olds started at the school when it was in its third year. The Montessori method relies on peer teaching and modeling, so those who are in the early classes of a new school lack some advantages relative to those who begin later.

Social/Behavioral Measures. As a social skills test, 12-year-olds read six stories about social problems (such as not being asked to a party) and were asked to choose among four responses. Montessori 12-year-olds were significantly more likely to choose the positive assertive

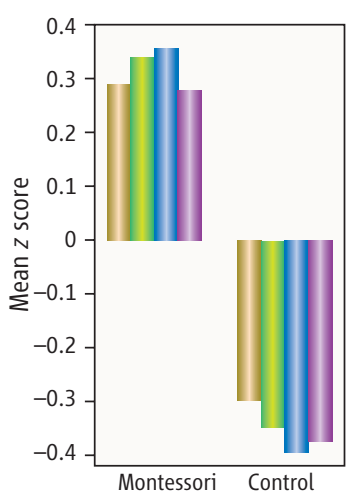

II Sophisticated sentence structures Creative story 11. Positive social strategies 11 Sense of school as community

Results for 12-year-olds. Students in the Montessori program wrote more sophisticated and creative stories and showed a more developed sense of community and social skills. Scores were converted to average $z$ scores (18). response (for example, verbally expressing one's hurt feelings to the host). On a questionnaire regarding their feelings about school, ontessori children indicated having a really care about each other," and "Students

\section{Benefits of Montessori Education}

On several dimensions, children at a public nontessori school had superior mes relative to a sample of Montessori social cognition and executive control. They also showed more concern for fairness and justice. At the end of elementary school, Montessori children wrote more creative essays with more complex sentence structures, selected more positive responses to sense of community at their school

These findings were obtained with a lottery genetic and envirc influences such as current or past school and day care environments. For example, in the Human Development (NICHD) study of early child care, correlations between parenting quality and WJ early academic tests had effect sizes comparable to those seen here, whereas school effects were much smaller (5). An evaluation of Success for All, considered a highly successful reading intervention, reported a quarter of a standard deviation as its largest effect size (for Word Attack) in a randomized field trial, and stated it was equal to a 4.69-month advance in reading skills (14). Stronger effects are often found in the first years of pilot programs when researchers are involved in implementation of their own programs (15), termed the "superrealization effect" (16). In our study, the school did not anticipate an evaluation. Especially remarkable outcomes of the Montessori education are the social effects, which are generally dominated by the home environment (17).

Future research could improve on the research design here by following lottery participants prospectively and by tracking those who drop out and examining their reasons. It would be useful to replicate these findings in different Montessori schools, which can vary widely. The school involved here was affiliated with AMI/USA, which has a traditional and relatively strict implementation. It would also be useful to know whether certain components of Montessori (e.g., the materials, or the opportunities for collaborative work) are associated with particular outcomes.

Montessori education has a fundamentally different structure from traditional education. At least when strictly implemented, Montessori education fosters social and academic skills that are equal or superior to those fostered by a pool of other types of schools.

\section{References and Notes}

1. M. Montessori, The Montessori Method (Schocken, New York, 1964).

2. A. S. Lillard, Montessori: The Science Behind the Genius (Oxford Univ. Press, New York, 2005).

3. Milwaukee Public Schools (http://mpsportal.milwaukee.k12.wi.us/portal/server.pt).

4. Association Montessori Internationale (www.montessoriami.org/).

5. NICHD Early Child-Care Research Network, Harvard Ed. Rev. 74, 1 (2004).

6. G. J. Duncan, W. J. Yeung, J. Brooks-Gunn, ]. R. Smith, Am. Soc. Rev. 63, 406 (1998).

7. K. S. McGrew, R. W. Woodcock, Woodcock-Johnson III Technical Manual (Riverside Publishing, Itasca, IL, 2001).

8. B. Hart, T. Risley, Meaningful Differences in the Everyday Experience of Young American Children (P.H. Brookes, Baltimore, MD, 1995).

11. K. H. Rubin. The social problem solving test-revised (Univ. of Waterloo, Waterloo, MI, 1988).

12. H. Wimmer, J. Perner, Cognition 13, 103 (1983)

11. C. Zimmer, Science 300, 1079 (2003).

12. J. Amsterlaw, H. Wellman, J. Cogn. Dev. 7, 139 (2006).

13. A. E. Cunningham, K. E. Stanovich, Dev. Psych. 33, 934 (1997).

14. G. D. Borman et al., Am. Ed. Res. J. 42, 673 (2005).

15. M. W. Lipsey, Ann. Am. Acad. Polit. Soc. Sci. 587, 69 (2003).

16. L. J. Cronbach et al., Toward Reform of Program Evaluation: Aims, Methods, and Institutional Arrangments (Jossey-Bass, San Francisco, 1980).

17. NICHD Early Child-Care Research Network, Am. Ed. Res. J. 42, 537 (2005).

18. The $z$-score conversion was used for the graph to give all tests the same metric. A $z$ score sets the mean (in this case of the entire sample) at 0 , one standard deviation above the mean at 1.68 , and one standard deviation below the mean at -1.68 .

19. Funding was provided by the Jacobs and Cantus Foundations and sabbatical fellowships from the Cattell Foundation and the University of Virginia to A.L. ]. DeLoache, B. Detmer, L. Ma, A. Pinkham, R. Tai, and ]. van Reet provided helpful comments, and E. Turkheimer provided valuable statistical advice. We thank the Milwaukee schools that participated; the children and their families; and A. Hart, T. Nishida, A. Pinkham, ] van Reet, and B. Rosen.

Supporting Online Material

www.sciencemag.org/cgi/content/ful//VOL]/[ISSUE]/[PAGE]/DC1 